\title{
Cardiorespiratory Failure in Thyroid Storm: Case Report and Literature Review
}

\author{
Qiang Nai ${ }^{\mathrm{a}, \mathrm{f}, \mathrm{g}, \text { Mohammad Ansari b, f, Stella Pak }}$, Yufei Tianª, Mohammed Amzad-Hossain, \\ Yanhong Zhang d, Yali Lou ${ }^{\mathrm{e}}$, Shuvendu Sen ${ }^{\mathrm{a}}$, Mohammed Islam ${ }^{\mathrm{b}}$
}

\begin{abstract}
Thyroid storm is a potentially fatal manifestation of thyrotoxicosis. Cardiopulmonary failure is the most common cause of death in thyroid storm. Clinicians should keep in mind that thyroid storm complicated with cardiopulmonary failure can be the first presentation of thyrotoxicosis. As early intervention is associated with improved patient outcome, prompt diagnosis based on clinical grounds is of paramount importance in the management of thyrotoxicosis. A high index of suspicion and the ability of early recognition of impending thyroid storm depends on a thorough knowledge of both the typical and atypical clinical features of this illness. Herein, we report a case of thyroid storm presenting as cardiopulmonary failure in a 51-year-old woman with undiagnosed Grave's disease. Additionally, we review the pathophysiology of cardiopulmonary failure associated with thyrotoxicosis and various treatment modalities for thyroid storm.
\end{abstract}

Keywords: Thyroid storm; Thyrotoxicosis; Grave's disease; Cardiopulmonary failure

\section{Introduction}

Thyroid storm is a debilitating complication from thyrotoxicosis. Thyroid storm is a status of dangerously higher levels of metabolic rate in all systems of the body, due to overproduction of the thyroid hormones. Common symptoms and signs

Manuscript submitted June 15, 2017, accepted July 3, 2017

${ }^{\text {aDDepartment }}$ of Medicine, University of Toledo Medical Center, Toledo, $\mathrm{OH}$ 43614, USA

bInternal Medicine, Raritan Bay Medical Center, Perth Amboy, NJ 08861, USA

'Department of Nephrology, New York Presbyterian Queens, 56-45 Main Street, Flushing, NY 11355, USA

dDepartment of Pulmonary and Critical Care, Jefferson University, 834 Walnut Street, Suite 650, Philadelphia, PA 19107, USA

eDepartment of Neurology, Brigham and Women's Hospital, 60 Fenwood Road, Boston, MA 02115, USA

${ }^{\mathrm{f}}$ These authors contributed equally

g Corresponding Author: Qiang Nai, University of Toledo Medical Center, Toledo, OH 43614, USA. Email: qiang.nai@utoledo.edu

doi: https://doi.org/10.14740/jocmr3106w of thyroid storm include the following: a sudden soaring of body temperature, racing heart rate or atrial fibrillation, high blood pressure, vomiting, diarrhea, dehydration, and changes in mental status. Thyroid storm occurs in $1-2 \%$ of individuals with hyperthyroidism, with Grave's disease being the most common cause. Although Grave's disease mostly occurs in young female, it can be seen in any genders or age groups. Thyroid storm can happen in solitary toxic adenoma or toxic multinodular goiter; and rarely in thyrotropin-secreting pituitary adenoma, hypersecretory thyroid carcinoma, struma ovarii/teratoma, human chorionic gonadotropia-secreting hydatidiform mole [1]. It can also be seen in thyrotoxicosis induced by $\alpha$-interferon or interleukin-2. Thyroid storm can be triggered by a number of other conditions including congestive heart failure, heart attack, pulmonary embolism, stroke, diabetic ketoacidosis, trauma, surgery, parturition, severe infection, and intense emotional distress. Thyroid storm may lead to failure of many organs including congestive heart failure. Being one of the most critical endocrine emergencies, thyroid storm is often fatal without immediate and aggressive management.

We present a case of thyroid storm presenting as cardiopulmonary failure in a patient with Grave's disease, where both anti-TPO and thyroid stimulating antibodies were detected [2]. The symptoms and signs our patient had corresponded well to the clinical picture of thyroid storm. This case underlines the importance of early recognition, immediate intensive and ongoing management.

\section{Case Report}

A 51-year-old African American female was sent to the emergency department for acute onset of severe respiratory distress. On admission, the vital signs are blood pressure 180/135 $\mathrm{mm} \mathrm{Hg}$, pulse $170 \mathrm{bpm}$, respiration rate 44/min, $\mathrm{O}_{2}$ saturation $70 \%$ on room air, temperature $38.3^{\circ} \mathrm{C}$. She was intubated immediately upon arrival because of respiratory failure. Patient was subsequently admitted to the intensive care unit for further management of possible severe status asthmaticus or congestive heart failure. Her past medical history was notable for asthma and hypertension. There was no known personal or family history of thyroid diseases. She reported chronic history of palpitations, anxiety, tremors, insomnia, and heat intolerance. She also complained of unintended body weight loss of $100 \mathrm{lbs}$ over last 3 years. Patient noticed gradual changes in 
Table 1. Arterial Blood Gas Test Results 30 min After Intubation

\begin{tabular}{lll}
\hline Arterial blood gas & Result & Normal range \\
\hline $\mathrm{pH}$ & 7.17 & $7.35-7.45$ \\
$\mathrm{PCO}_{2}$ & 62.3 & $35.0-45.0 \mathrm{~mm} \mathrm{Hg}$ \\
$\mathrm{PO}_{2}$ & 314.0 & $75.0-100.0 \mathrm{~mm} \mathrm{Hg}$ \\
$\mathrm{HCO}_{3}$ & 22.1 & $23.0-28.0 \mathrm{mmol} / \mathrm{L}$ \\
$\mathrm{O}_{2}$ sat & $99.7 \%$ & $94-98 \%$ \\
$\mathrm{FiO}_{2}$ & $100 \%$ & \\
\hline A-a gradient & 328.7 & \\
\hline
\end{tabular}

her eyes, but no pain or tenderness in the neck. She denied ingestion of iodine, kelp or seaweed. Patient did not seek medical assistance for those symptoms.

Physical examination revealed exophthalmos of right eye, goiter, tachycardia, and hand tremors. Laboratory test revealed hypercapnic respiratory failure (Table 1), mildly elevated troponin I levels (Table 2), markedly suppressed thyroid-stimulating hormone (TSH) and elevated T3 and T4 levels (Table 3). EKG on admission showed sinus tachycardia, left atrial abnormality (Fig. 1). Chest X-ray demonstrated extensive bilat-

Table 2. Laboratory Findings

\begin{tabular}{lll}
\hline Test & Result & Normal Range \\
\hline Sodium & 137 & $136-145 \mathrm{mEq} / \mathrm{L}$ \\
Potassium & 3.8 & $3.5-5.1 \mathrm{mEq} / \mathrm{L}$ \\
Chloride & 98 & $90-110 \mathrm{mEq} / \mathrm{L}$ \\
Bicarbonate & 21 & $22-28 \mathrm{mEq} / \mathrm{L}$ \\
Blood urea nitrogen & 9 & $6-20 \mathrm{mg} / \mathrm{dL}$ \\
Creatinine & 0.6 & $0.5-0.9 \mathrm{mg} / \mathrm{dL}$ \\
Glucose & 179 & $70-115 \mathrm{mg} / \mathrm{dL}$ \\
Calcium & 10.7 & $8.6-10.2 \mathrm{mg} / \mathrm{dL}$ \\
Magnesium & 1.7 & $1.7-2.5 \mathrm{mg} / \mathrm{dL}$ \\
AGP & 19 & $2.6-10.6 \mathrm{mmol} / \mathrm{L}$ \\
GFRAA & $>60$ & $\geq 60 \mathrm{~mL} / \mathrm{min} / 1.73 \mathrm{~m}{ }^{2}$ \\
Alkaline phosphatase & 175 & $40-130 \mathrm{U} / \mathrm{L}$ \\
Troponin I & $0.51 \rightarrow 0.43 \rightarrow 0.56<0.3 \mathrm{ng} / \mathrm{mL}$ \\
CK & $47.0 \rightarrow 83.0 \rightarrow 67.0$ & $20-200 \mathrm{ng} / \mathrm{mL}$ \\
CKMB & $2.53 \rightarrow 6.1 \rightarrow 4.86$ & $1.0-5.0 \mathrm{ng} / \mathrm{mL}$ \\
BNP & $2,380.0$ & $<300$ \\
HGB & 14.8 & $10.3-15.1$ \\
HCT & $47.6 \%$ & $31.2-45.4 \%$ \\
WBC & 13.6 & $3.6-11.0$ \\
Platelet & 233 & $150-372$ \\
Absolute lymphocyte & 6.3 & $0.9-2.9$ \\
\hline
\end{tabular}

AGP: anion gap; BNP: brain natriuretic peptide; CK: creatinine phosphokinase; GFRAA: estimated glomerular filtration rate for African American; HGB: hemoglobin; HCT: hematocrit; WBC: white blood cell.
Table 3. Thyroid Panel

\begin{tabular}{lll}
\hline Tests & Results & Normal range \\
\hline T3 total & 269 & $71-180 \mathrm{ng} / \mathrm{dL}$ \\
T3 free & 10 & $2.0-4.4 \mathrm{pg} / \mathrm{mL}$ \\
Free T4 & 5.05 & $0.82-1.77 \mathrm{ng} / \mathrm{dL}$ \\
$\mathrm{TSH}$ & 0.005 & $0.45-4.50 \mu \mathrm{IU} / \mathrm{mL}$ \\
$\mathrm{TPO} \mathrm{Ab}$ & 67.0 & $0-34 \mathrm{IU} / \mathrm{mL}$ \\
$\mathrm{TSAb}$ & 446 & $0-139 \%$ \\
$\mathrm{TgAb}$ & $<20$ & $0-40 \mathrm{IU} / \mathrm{mL}$ \\
PTH & 74 & $15-65 \mathrm{pg} / \mathrm{mL}$ \\
\hline
\end{tabular}

TPO Ab: thyroid peroxidase antibody; TgAb: thyroglobulin antibody; TSAb: thyroid-stimulating antibody.

eral airspace disease compatible with pulmonary edema and/or pneumonia (Fig. 2). Echocardiogram showed left ventricular (LV) ejection fraction of 50\%, normal LV size and thickness; mild to moderate mitral regurgitation with an eccentric jet, thickened mitral valve, mild tricuspid regurgitation; and aneurysmal atrial septum. Subsequent thyroid sonogram showed multinodular goiter with the largest nodule of $3.6 \mathrm{~cm}$ in isthmus (Fig. 3). Thyroid scan/ UPTK $\left(\mathrm{I}^{123}\right)$ revealed marked increased uptake at 4 and $24 \mathrm{~h}$, suggesting hyperthyroidism (Fig. 4).

In addition to methylprednisolone given for asthma exacerbation, our patient was also started on treatment for non-ST segment elevation myocardial infarction with mildly elevated troponin I levels (Table 2), including heparin drip, metoprolol, among others. Heparin drip was discontinued since the elevated troponin I level was most likely due to thyrotoxic cardiomyopathy. Patient was subsequently started on methimazole for thyrotoxicosis. The symptoms were well controlled and patient was subsequently discharged home on medical treatment for hyperthyroidism due to Grave's disease. Patient remained asymptomatic during a 2-year follow-up after discharge.

\section{Discussion}

Thyroid disease is a common illness affecting $9 \%$ to $15 \%$ of the adult. In adult population, thyroid disease affects women more often than men [3]. This gender difference can most likely be attributed to the underlying autoimmune mechanism for the vast majority of thyroid diseases, including Graves' and Hashimoto's disease [4]. However, this sex difference becomes less prominent with advancing ages, especially beyond the age of 80 [3]. Both hyperthyroidism and hypothyroidism cause derangement in heart and vasculature [5]. It is well known that hyperthyroidism induces tachycardia, enhances left ventricular systolic and diastolic function, and increases occurrence of supraventricular tachyarrhythmia, such as atrial fibrillation. On the other hand, hypothyroidism exerts largely opposite effects on cardiovascular system. However, it is worth mentioning that hypothyroidism predisposes patients to systemic hypertension [5, 6] and ventricular tachycardia [7].

Thyrotoxicosis refers to the clinical syndrome of hyper- 


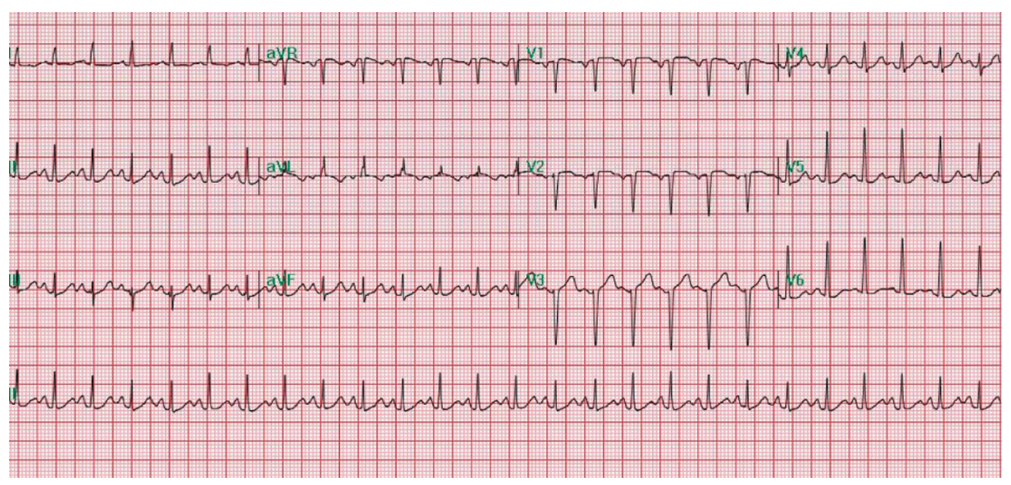

Figure 1. EKG on admission showed sinus tachycardia (heart rate: $149 \mathrm{bpm}$ ) and left atrial abnormality.

metabolism due to excessive amount of circulating thyroid hormones [8]. Thyrotoxicosis can result from the destruction of thyroid follicles and thyrocytes as in thyroiditis, excessive exogenous thyroid hormone intake, or hyperthyroidism that is defined as inappropriate increase in the biosynthesis and secretion of thyroid hormones by thyroid glands [9]. Graves' disease is the most common form of thyrotoxicosis. Thyroid storm, also known as thyrotoxic crisis, is a rare acute hypermetabolic state resulting from excessive release of thyroid hormones. It mostly occurs in individuals with untreated or undertreated thyrotoxicosis. Thyroid storm can be precipitated by trauma, surgery, or infection. Common symptoms and signs of thyroid storm include hyperthermia, tachycardia, hypertension, nausea, vomiting, tremulousness, agitation, and psychosis. Thyroid storm also can cause stupor or coma. Congestive heart failure may occur and lead to hypotension and shock [10].

Thyroid storm is almost always fatal without proper treatment. Cardiopulmonary failure is the most common cause of death in thyroid storm, particularly in elderly patients [11]. Fortunately, owing to the advance of diagnosis and therapeutic strategies, the mortality of this disorder has dropped from nearly $100 \%$ to $10 \%$ [12]. However, since laboratory confirmation is often delayed, thyroid storm must be diagnosed promptly on clinical grounds to allow expeditious provision of life-saving treatment. Therefore, a high index of suspicion and the ability of early diagnosis of impending thyroid storm is critical, which are in turn dependent on a thorough knowledge of both the typical and atypical clinical features of this illness.

A point system has been proposed to standardize the definition of thyroid storm. The point system consists of parameters of thermoregulatory, central nervous system, gastrointestinalhepatic, cardiovascular dysfunction (tachycardia, congestive heart failure, atrial fibrillation), and previous history of thyroid storm. A score of 45 or greater is highly suggestive of thyroid storm. However, in practice, it would be prudent to start aggressive and immediate management as soon as impending thyroid storm is suspected. According to the thyroid storm diagnosis point system ( $\geq 45$ for thyroid storm), the score of our patient is at least 75 , confirming the diagnosis of thyroid storm [12].

In our case, an acute cardiorespiratory failure was closely associated with the thyroid storm resulting from an undiagnosed Graves' disease. The cardiopulmonary failure in thyroid storm might be attributed to several possible etiologies associated with thyroid storm: 1) respiratory muscle failure, 2) cardiac failure, and 3) hypokalemia.

\section{Thyroid storm and respiratory muscle failure}

The presenting symptoms of hypercapnia and rapid improvement of symptoms after intubation make it plausible that respiratory muscle fatigue and failure is involved in our case. Neurological or non-neurological causes may be involved.
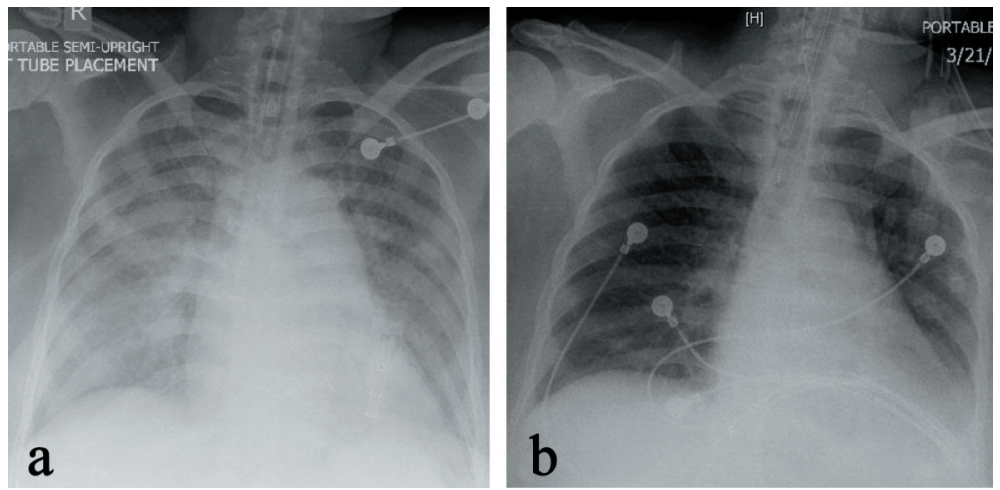

Figure 2. Chest X-ray on admission (a) revealed extensive bilateral airspace disease compatible with pulmonary edema, which significantly cleared up on the second day of admission (b). 

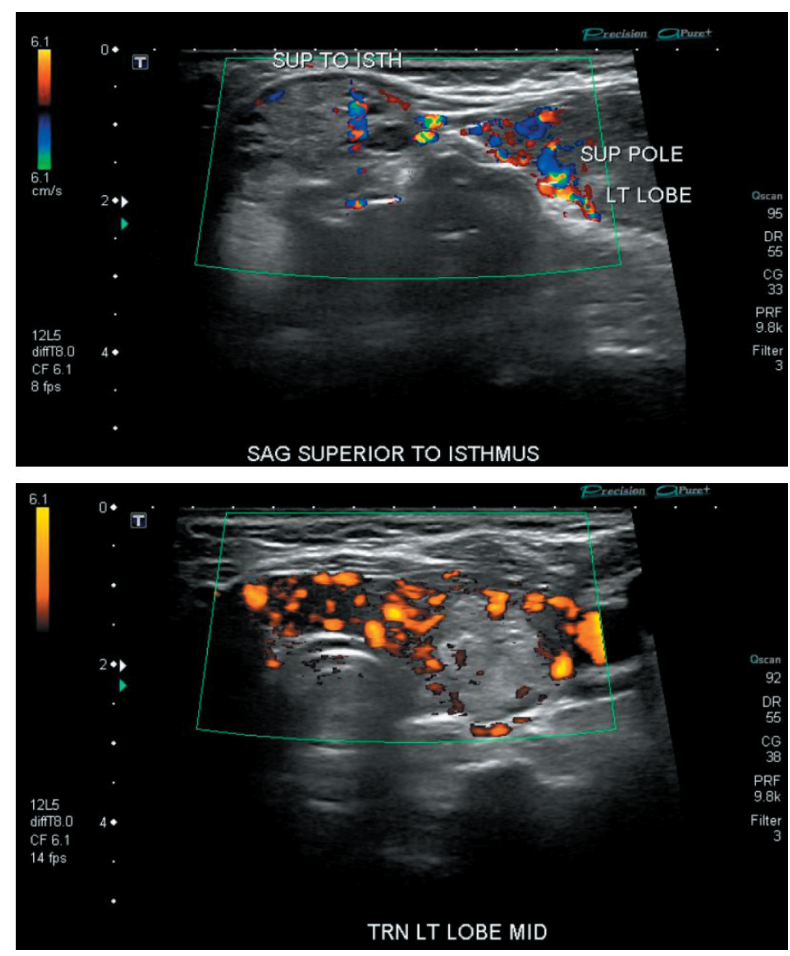

Figure 3. Ultrasound detected multiple nodules in thyroid gland.

Among the possible non-neurological causes, increased work of breathing and acidosis are very likely involved in an asthmatic patient. The preexisting asthma not only decreases the compensatory capacity of the respiratory system, but also the associated hyperpneic status may compromise the respiratory muscles and subsequently respiratory muscle fatigue. Otherwise, muscle mass can be reduced by approximately $20 \%$ and muscle strength by approximately $40 \%$ in patients with thyrotoxicosis [13]. Both inspiratory and expiratory muscles are affected by thyrotoxicosis [14]. Significant functional weakness of diaphragm muscle has been demonstrated in active Graves' disease. Interestingly, this weakness is more prominent during maximal respiratory efforts, implying a diminished diaphragmatic reserve [15]. Severe involvement of the respiratory muscles may cause respiratory failure [16], and fatigue of the inspiratory muscles by itself may leads to acute respiratory acidosis, this may result in a vicious cycle. Inspiratory muscle fatigue and failure requires mechanical ventilation to put these muscles to rest [17].

Thyrotoxic myopathy in Graves' disease is possibly another important factor contributing to muscle fatigue and failure in our case [18]. Thyroid myopathy may manifest as respiratory failure. Hyperthyroidism likely causes damage to the motor end plates from pre- or postsynaptic side of the motor end plate, or a combination $[19,20]$. Polymyositis has been reported in one patient of Grave's disease [18]. Rhabdomyolysis can also occur in thyrotoxicosis [21], however the normal creatine phosphokinase (CK) levels in our patient argued against the degeneration of muscle that is characteristic of myopathy (Table 2).

Other non-neurological factors that are related to respira-

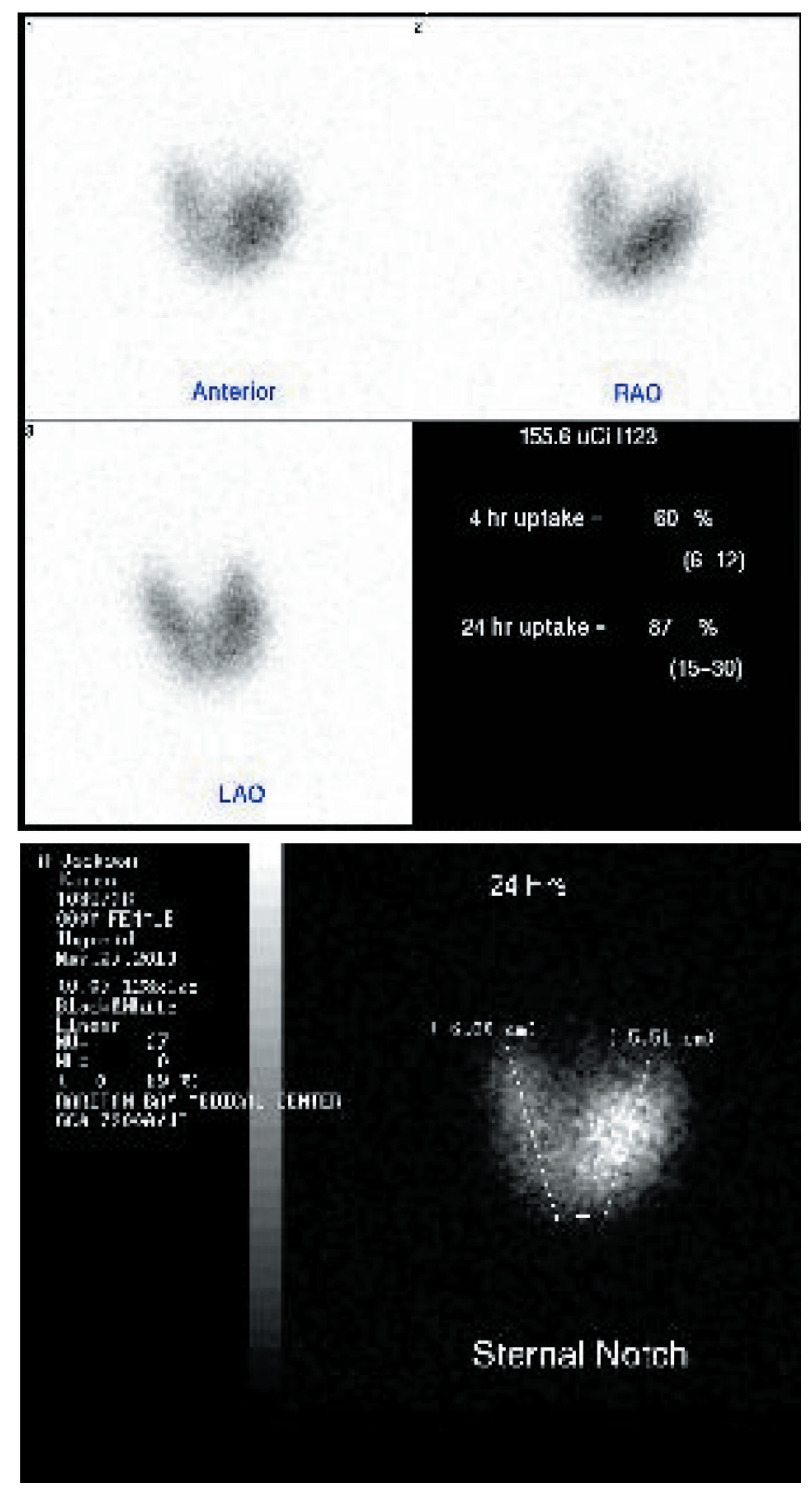

Figure 4. Thyroid scan revealed hot spots in thyroid glands.

tory muscle failure include deficiency of potassium, magnesium, and inorganic phosphorus, mechanical disadvantage, impaired nutritional status, shock, and hypoxemia [17]. Those were less likely the contributing factors in our case. Furthermore, although we cannot completely exclude other neurological etiologies, the transient feature in our case and the absence of prior history of neurological diseases make them less likely the underlying mechanisms.

Occasionally thyrotoxic periodic paralysis (TPP) may cause respiratory failure. TPP is characterized by acute onset of severe hypokalemia resulting from an increased $\mathrm{Na} / \mathrm{K}$-ATPase activity [22], and profound proximal muscle weakness in patients with thyrotoxicosis. Hypophosphatemia and mild hypomagnesemia are additional characteristic features [23]. TPP occurs more frequently in Asian population [24]. This is unlikely related to the symptoms in our patient, since there was no periodic paralysis or hypokalemia on admission. 


\section{Thyroid storm and cardiovascular system}

Most patients with thyrotoxicosis develop cardiovascular manifestations, which are also the most severe complications of this condition $[24,25]$. The hyperdynamic state of cardiovascular system is the most recognizable manifestation, featuring increased resting heart rate, enhanced left ventricular contractility and blood volume, but decreased systemic vascular resistance $[26,27]$. There are two clinical observations related to cardiovascular system in thyrotoxicosis, the more frequent one is reduced exercise tolerance [28, 29]; another one, although rarely, is the severe symptomatic congestive heart failure in thyrotoxicosis $[29,30]$ through a tachycardia-mediated mechanism $[5,27,30]$. Heart failure develops in $6 \%$, but dilated cardiomyopathy with impaired left ventricular systolic function in less than $1 \%$ of thyrotoxic individuals. An increased level of cytosolic calcium during diastole with impaired ventricular contractility and diastolic dysfunction was likely involved. An often associated symptom is tricuspid regurgitation [27]. The impaired cardiac contractility and low cardiac output mostly occur in patients with preexisting heart diseases [31]. Not surprisingly, the sustained sinus tachycardia or atrial fibrillation can further impair the systolic function in thyrotoxicosis [32]. Another cardiovascular change in thyrotoxicosis is the isolated right-sided heart failure secondary to pulmonary artery hypertension [27]. Heart failure on both sides is reversible if the underlying thyrotoxicosis is recognized and treated early $[33,34]$. Control of heart rate can improve or completely resolve the cardiomyopathy in tachycardia-induced heart failure [35], which is evinced again by the rapid improvement of the pulmonary congestion in our case (Fig. 2).

It is worth noting that, as in our case a small increase in troponin in thyroid storm may not necessarily be due to atherosclerotic coronary artery disease, but a result of tachycardia [36], coronary artery spasm [37], Takotsubo cardiomyopathy $[38,39]$.

Hyperparathyroidism also occurred in reported case (Table 2). The coexistence of hyperthyroidism and hyperparathyroidism is rare and the hyperparathyroidism in some cases is likely a secondary disease [40]. However, it has been suggested that parathyroidism must be excluded, and surgical exploration is required if hypercalcemia persists after achievement of euthyroidism [41].

\section{Management of thyroid storm}

Medical treatment of thyroid storm may follow these principles: 1) supportive care and management of systemic complications, such as cardiorespiratory failure, and controlling precipitating factors, 2) control the peripheral effects of thyroid hormones, 3 ) inhibit synthesis and release of thyroid hormone.

Systemic decompensation may occur and supportive measures are required to stabilize the patients immediately, including intravenous fluids with dextrose, oxygen, ventilatory support, correction of electrolyte abnormalities, control of cardiac arrhythmia, aggressive management of hyperthermia using acetaminophen, or physical methods of cooling.
Antiadrenergic agents should be administrated immediately to minimize sympathomimetic symptoms. However, extreme caution should be taken in patients with decompensated systolic heart failure or other contraindications. Non-selective beta blockers were found to have more direct effect on hypermetabolism and are preferred in the treatment of thyrotoxicosis. Propranolol is widely used for prompt relief of sympathetic symptoms, including tremor, tachycardia, heat intolerance, and anxiety. The dose of propranolol can be started from 10 - $20 \mathrm{mg}$ every $6 \mathrm{~h}$, and can be adjusted up to 80 - $320 \mathrm{mg} /$ day to achieve sufficient symptom control. Other longer-acting beta blockers such as atenolol may be preferred for their more convenient dosage. If beta blockers are not tolerated, calcium channel blockers such as diltiazem are an alternative for heart rate control $[42,43]$.

Thionamides such as propylthiouracil (PTU) or methimazole should also be administrated promptly. These medications start to block thyroid hormone synthesis within 1 to $2 \mathrm{~h}$. In addition to inhibition of thyroid hormone synthesis, PTU also decreases $\mathrm{T} 4$ to $\mathrm{T} 3$ conversion.

Iodine compounds can block the release of thyroid hormones from thyroid glands within hours. Since administrated iodine can be used for synthesis of new thyroid hormones, such iodine-containing solutions should be given at least $1 \mathrm{~h}$ after thionamide administration. Glucocorticoids, such as hydrocortisone or dexamethasone not only decrease peripheral conversion of T4 to T3, but also help prevent adrenal insufficiency due to severe thyrotoxicosis and improve vasomotor symptoms [44]. Bile acid sequestrants can reduce thyroid hormones by interfering with the enterohepatic circulation and increasing their fecal excretion. Cholestyramine is a safe and effective agent for adjunctive therapy of thyrotoxicosis [45].

Clinical improvement is expected within $12-24 \mathrm{~h}$ of medical treatment. Further treatment, including radioactive iodine or surgery, may be employed in late phases. Early thyroidectomy is the treatment of choice if medical therapy fails, or in patients who cannot take thionamides. Preparation for thyroidectomy includes about 1-week supportive treatment of thyrotoxicosis, which often consists of beta blockers, iodine compounds, glucocorticoids, and bile acid sequestrants. Plasmapheresis may be used as supportive therapy in preparation for thyroidectomy if the traditional measures are ineffective $[11,46-48]$.

\section{Conclusions}

Thyroid storm complicated with cardiopulmonary failure can be the initial presentation of undiagnosed thyrotoxicosis. As cardiopulmonary failure is the most common cause of death in thyroid storm, prompt diagnosis and treatment is critical in the survival of patients. In addition to the medical treatment to control the sympathomimetic symptoms and inhibit synthesis and release of thyroid hormones, as well as supportive measures for systemic decompensation, the precipitating factors of thyroid storm should be searched and corrected. Radioactive iodine or surgery can be used as definitive treatment for patients with Graves' disease, toxic multinodular goiter, or toxic adenoma. 


\section{References}

1. Nayak B, Burman K. Thyrotoxicosis and thyroid storm. Endocrinol Metab Clin North Am. 2006;35(4):663-686, vii.

2. Trbojevic B, Djurica S. [Diagnosis of autoimmune thyroid disease]. Srp Arh Celok Lek. 2005;133(Suppl 1):2533.

3. Canaris GJ, Manowitz NR, Mayor G, Ridgway EC. The Colorado thyroid disease prevalence study. Arch Intern Med. 2000;160(4):526-534.

4. Volpe R. Immunoregulation in autoimmune thyroid disease. Thyroid. 1994;4(3):373-377.

5. Fazio S, Palmieri EA, Lombardi G, Biondi B. Effects of thyroid hormone on the cardiovascular system. Recent Prog Horm Res. 2004;59:31-50.

6. Fommei E, Iervasi G. The role of thyroid hormone in blood pressure homeostasis: evidence from short-term hypothyroidism in humans. J Clin Endocrinol Metab. 2002;87(5):1996-2000.

7. Fredlund BO, Olsson SB. Long QT interval and ventricular tachycardia of "torsade de pointe" type in hypothyroidism. Acta Med Scand. 1983;213(3):231-235.

8. Braverman L, Utiger R. Introduction to thyrotoxicosis. In: Braverman L, Utiger R eds. The Thyroid. 9th ed. Philadelphia: Lippincott Williams \& Wilkins; 2005; 453-455.

9. Reinwein D, Benker G, Konig MP, Pinchera A, Schatz H, Schleusener A. The different types of hyperthyroidism in Europe. Results of a prospective survey of 924 patients. J Endocrinol Invest. 1988;11(3):193-200.

10. Chiha M, Samarasinghe S, Kabaker AS. Thyroid storm: an updated review. J Intensive Care Med. 2015;30(3):131140.

11. Scholz GH, Hagemann E, Arkenau C, Engelmann L, Lamesch P, Schreiter D, Schoenfelder M, et al. Is there a place for thyroidectomy in older patients with thyrotoxic storm and cardiorespiratory failure? Thyroid. 2003;13(10):933-940.

12. Burch HB, Wartofsky L. Life-threatening thyrotoxicosis. Thyroid storm. Endocrinol Metab Clin North Am. 1993;22(2):263-277.

13. Norrelund H, Hove KY, Brems-Dalgaard E, Jurik AG, Nielsen LP, Nielsen S, Jorgensen JO, Weeke J, Moller N. Muscle mass and function in thyrotoxic patients before and during medical treatment. Clin Endocrinol (Oxf). 1999;51(6):693-699.

14. Siafakas NM, Milona I, Salesiotou V, Filaditaki V, Tzanakis N, Bouros D. Respiratory muscle strength in hyperthyroidism before and after treatment. Am Rev Respir Dis. 1992;146(4):1025-1029.

15. Goswami R, Guleria R, Gupta AK, Gupta N, Marwaha RK, Pande JN, Kochupillai N. Prevalence of diaphragmatic muscle weakness and dyspnoea in Graves' disease and their reversibility with carbimazole therapy. Eur J Endocrinol. 2002;147(3):299-303.

16. Mier A, Brophy C, Wass JA, Besser GM, Green M. Reversible respiratory muscle weakness in hyperthyroidism. Am Rev Respir Dis. 1989;139(2):529-533.

17. Rochester DF, Arora NS. Respiratory muscle failure. Med
Clin North Am. 1983;67(3):573-597.

18. Sakata S, Fuwa Y, Goshima E, Nakamura S, Yamakita N, Maeda M, Miura K. A case of Graves' disease associated with polymyositis. J Endocrinol Invest. 1989;12(11):837840.

19. Kazakov VM. Terminal intramuscular motor innervation and motor end-plates in thyrotoxic myopathy. Neuromuscul Disord. 1992;2(5-6):343-349.

20. Asayama K, Kato K. Oxidative muscular injury and its relevance to hyperthyroidism. Free Radic Biol Med. 1990;8(3):293-303.

21. Lichtstein DM, Arteaga RB. Rhabdomyolysis associated with hyperthyroidism. Am J Med Sci. 2006;332(2):103105.

22. Lam L, Nair RJ, Tingle L. Thyrotoxic periodic paralysis. Proc (Bayl Univ Med Cent). 2006;19(2):126-129.

23. Manoukian MA, Foote JA, Crapo LM. Clinical and metabolic features of thyrotoxic periodic paralysis in $24 \mathrm{epi}$ sodes. Arch Intern Med. 1999;159(6):601-606.

24. McFadzean AJ, Yeung R. Periodic paralysis complicating thyrotoxicosis in Chinese. Br Med J. 1967;1(5538):451455.

25. Fadel BM, Ellahham S, Ringel MD, Lindsay J, Jr., Wartofsky L, Burman KD. Hyperthyroid heart disease. Clin Cardiol. 2000;23(6):402-408.

26. Nordyke RA, Gilbert FI, Jr., Harada AS. Graves' disease. Influence of age on clinical findings. Arch Intern Med. 1988;148(3):626-631.

27. Dahl P, Danzi S, Klein I. Thyrotoxic cardiac disease. Curr Heart Fail Rep. 2008;5(3):170-176.

28. Kahaly GJ, Nieswandt J, Wagner S, Schlegel J, MohrKahaly S, Hommel G. Ineffective cardiorespiratory function in hyperthyroidism. J Clin Endocrinol Metab. 1998;83(11):4075-4078.

29. Kahaly GJ, Wagner S, Nieswandt J, Mohr-Kahaly S, Ryan TJ. Stress echocardiography in hyperthyroidism. J Clin Endocrinol Metab. 1999;84(7):2308-2313.

30. Magner JA, Clark W, Allenby P. Congestive heart failure and sudden death in a young woman with thyrotoxicosis. West J Med. 1988;149(1):86-91.

31. Schmidt-Ott UM, Ascheim DD. Thyroid hormone and heart failure. Curr Heart Fail Rep. 2006;3(3):114-119.

32. Riaz K, Forker AD, Isley WL, Hamburg MS, McCullough PA. Hyperthyroidism: a "curable" cause of congestive heart failure - three case reports and a review of the literature. Congest Heart Fail. 2003;9(1):40-46.

33. Khandwala HM. A case of congestive heart failure due to reversible dilated cardiomyopathy caused by hyperthyroidism. South Med J. 2004;97(10):1001-1003.

34. Al-Ghamdi AS, Aljohani N. Graves' thyrotoxicosisinduced reversible cardiomyopathy: a case report. Clin Med Insights Case Rep. 2013;6:47-50.

35. Patel JJ, Whittaker CT. Tachycardia-induced heart failure. Perm J. 2007;11(3):50-52.

36. Kanjwal K, Imran N, Grubb B, Kanjwal Y. Troponin elevation in patients with various tachycardias and normal epicardial coronaries. Indian Pacing Electrophysiol J. 2008;8(3):172-174.

37. Chudleigh RA, Davies JS. Graves' thyrotoxicosis and 
coronary artery spasm. Postgrad Med J. 2007;83(985):e5.

38. Eliades M, El-Maouche D, Choudhary C, Zinsmeister B, Burman KD. Takotsubo cardiomyopathy associated with thyrotoxicosis: a case report and review of the literature. Thyroid. 2014;24(2):383-389.

39. Zhou D, Qu Z, Wang H, Wang Z, Xu Q. Severe hyperthyroidism presenting with acute st segment elevation myocardial infarction. Case Rep Cardiol. 2015;2015:901214.

40. Bergdahl L. Hyperparathyroidism in thyrotoxicosis. Am J Surg. 1977;133(2):206-210.

41. Richards AJ. Hypercalcaemia in thyrotoxicosis with and without hyperparathyroidism. Postgrad Med J. 1970;46(537):440-446.

42. Geffner DL, Hershman JM. Beta-adrenergic blockade for the treatment of hyperthyroidism. Am J Med. 1992;93(1):61-68.

43. Ginsberg J. Diagnosis and management of Graves' disease. CMAJ. 2003;168(5):575-585.

44. Tsatsoulis A, Johnson EO, Kalogera CH, Seferiadis K,
Tsolas O. The effect of thyrotoxicosis on adrenocortical reserve. Eur J Endocrinol. 2000;142(3):231-235.

45. Tsai WC, Pei D, Wang TF, Wu DA, Li JC, Wei CL, Lee $\mathrm{CH}$, et al. The effect of combination therapy with propylthiouracil and cholestyramine in the treatment of Graves' hyperthyroidism. Clin Endocrinol (Oxf). 2005;62(5):521-524.

46. Migneco A, Ojetti V, Testa A, De Lorenzo A, Gentiloni Silveri N. Management of thyrotoxic crisis. Eur Rev Med Pharmacol Sci. 2005;9(1):69-74.

47. Carroll R, Matfin G. Endocrine and metabolic emergencies: thyroid storm. Ther Adv Endocrinol Metab. 2010;1(3):139-145.

48. Bahn RS, Burch HB, Cooper DS, Garber JR, Greenlee $\mathrm{MC}$, Klein I, Laurberg P, et al. Hyperthyroidism and other causes of thyrotoxicosis: management guidelines of the American Thyroid Association and American Association of Clinical Endocrinologists. Endocr Pract. 2011;17(3):456-520. 